\title{
Evaluation of transperineal ultrasound in diagnosis and grading of female genuine urinary stress incontinence
}

\author{
Abstract \\ Stress urinary incontinence (SUI) has an observed prevalence of between $4 \%$ and $35 \%$. \\ Purpose: To determine the role of transperineal ultrasound in diagnosing stress \\ incontinence, its degree and the possible cause by: \\ a. Measuring the $\mathrm{BN}$ descent, urethral hypermobility, funneling of $\mathrm{BN}$ or proximal \\ urethra, urethral diameter, posterior urethra vesical angle, associated cystocele \\ b. Using color Doppler to detect escape of urine through the urethra.
}

Methods: 52 female patients diagnosed to have genuine stress incontinence using 3 day voiding diary, simple questionnaire and confirmed by standard urodynamics. Classification of stress incontinence into mild, moderate and severe using Valsalva leak point pressure during urodynamic study. Transperineal ultrasound for evaluation of the anterior pelvic compartment regarding: bladder neck descent, urethralhy permobility, Funneling of the $\mathrm{BN}$, posterior urethrovesical angle, urethral diameter, associatedcystocele, and finally the Doppler detection of urinary escape both at rest and with Valsalva maneuvers.

Results: $28 / 52$ cases (53.8\%) of SUI didn't show clinical evidence of cystocele; 11 cases $(21.2 \%)$ showed grade 1 cystocele and 13 cases $(25 \%)$ showed grade 2 cystocele. The presence or absence of cystocele and also the grade of cystocele did not show a statistically significant relation to the degree of SUI; $\mathrm{p}=0.089$ and 0.086 respectively

Conclusion: We came to conclusion that transperineal ultrasound can be used in accurate diagnosis and grading of female urinary stress incontinence with our given cutoff values for bladder displacement, $\alpha$ angle, $\beta$ angle and urethral diameters and from this grading by transperineal ultrasound comes the novelity of our research.

Keywords: female stress urinary incontinence, trans perineal ultrasound, urodynamic, urethralhy permobility, intrinsic phincteric deficiency
Volume II Issue I - 2020

\begin{abstract}
Ahmed El lithy
Department of Obstetrics and Gynecology, Kasralainy faculty of medicine, Cairo university, Egypt
\end{abstract}

Correspondence: Ahmed El lithy, Department of Obstetrics and Gynecology, Kasralainy faculty of medicine, Cairo university, Egypt, Email ahmedellithy7@gmail.com

Received: February 07, 2020 | Published: February 25, 2020
Abbreviations: SUI, stress urinary incontinence; USI, urodynamic stress incontinence; VLPP, valsalva leak point pressure; ISD, intrinsic sphincteric deficiency; BN, bladder neck descent; PUVA, posterior urethrovesical angle; ROC, receiver operator characteristic

\section{Introduction}

The International Continence Society's terminology committee has organized lower urinary tract dysfunction into the logical sequence of symptoms, signs, and urodynamic diagnosis.

The symptom, or "subjective indicator of disease," of SUI is described as "the complaint of involuntary leakage on effort or exertion, or on sneezing or coughing". ${ }^{1}$

Stress urinary incontinence (SUI) has an observed prevalence of between $4 \%$ and $35 \%$. ${ }^{2,3}$

It is a social problem that causes hygienic problem which is distressing for females. Urodynamic study is the gold standard for diagnosis of most types of urinary incontinence with some limitations as it is not done routinely in all cases of urinary incontinence according to the NICE guidelines. ${ }^{2}$

Transperineal ultrasound is a simple, noninvasive, available, and reproducible method for qualitative and quantitative evaluation of the lower urinary tract in females.

Many authors studied the relation of the bladder neck to the symphysis pubis, the hypermobility of urethra, the urethral diameter and the posterior urethrovesical angle. ${ }^{4}$

Interpretation suggested comparable data as given by urodynamic study. 5,6

\section{Aim}

To evaluate the effectiveness of the transperineal ultrasound in diagnosing and grading of stress urinary incontinence in females and in detecting the anatomical defect which may be useful in deciding the type of surgery.

\section{Methods}

This is an observational cross sectional study carried in Kasr Al Aini Teaching Hospital-Cairo University in the period between January 2018 to January 2019.

52 female patients were recruited from the one stop urogynecology clinic having genuine stress urinary incontinence. An informed written consent was obtained from all patients who consented to participate in 
the study and the study received approval of the Scientific and Ethical committee before starting patient enrollment into the study.

\section{Ethical approval}

All procedures performed in studies involving human participants were in accordance with the ethical standards of the institutional and/ or national research committee and with the 1964 Helsinki declaration and its later amendments or comparable ethical standards.

\section{Inclusion criteria}

i. Any age

ii. Women with genuine stress urinary incontinence as diagnosed by history taking, voiding diary, examination and confirmed by urodynamicstudy.

\section{Exclusion criteria:}

a) Known to be diabetic

b) Urinary tract infection

c) Urge incontinence or mixed type

d) Voiding dysfunction

e) Neurological problems

f) Open suprapubic wound

g) Previous surgery for POP or incontinence

\section{Protocol of study}

\section{Initial visit}

a. Detailed history taking including (present, parity, surgical, medical, and family history)

b. Examination including (general, abdominal, neurological, urogynecological and with digital assessment of pelvic floor muscle contraction)

c. Complete urine analysis for the presence of blood, glucose, protein, leucocytes and nitrites.

d. Patients with urinary tract infection were treated and excluded from the study.

e. Patients were then classified according to symptoms into stress, urge incontinence and mixed.

f. Only patients with stress incontinence were selected and asked to fill a 3-day voiding diary.

\section{Next visit}

Patients confirmed by the voiding diary to have stress incontinence were sent for urodynamic study.

Urodynamic stress incontinence (USI) is the demonstration of involuntary leakage of urine during increased abdominal pressure but in the absence of detrusor contraction during the filling phase of urodynamics.

Valsalva leak point pressure (VLPP) is the minimum total vesical pressure required to cause urinary incontinence in the absence of detrusor contraction, at which urinary leakage occurs during progressive increases in intra-abdominal pressure by Valsalva maneuvers (McGuire, 1993).
The bladder was filled to $200 \mathrm{ml}$ with regular saline while sitting.

Using a pressure gauge, the patient is asked to blow while relaxing the pelvic floor to increase the vesical pressure, and observing for urine leak.

According to Valsalva leak point pressure, stress incontinence is graded into

i. Mild VLPP $>90 \mathrm{~cm} \mathrm{H}_{2} \mathrm{O}$ suggests urethral hypermobility with minimal ISD

ii. Moderate VLPP $60-90 \mathrm{~cm} \mathrm{H}_{2} \mathrm{O}$ is equivocal for both urethral hypermobility and ISD

iii. Severe VLPP $<60 \mathrm{~cm} \mathrm{H}_{2} \mathrm{O}$ evident for presence of intrinsic sphincteric deficiency (ISD) ${ }^{7}$

\section{Transperineal ultrasound}

Patients selected after urodynamic confirmation was referred for an ultrasound scan using a Voluson 730 Pro machine (GE medical systems) mounted with $3.5 \mathrm{MHZ}$ convex array.

Patients resting in the dorsolithotomy position with the bladder filled with approximately $200 \mathrm{ml}$ saline estimated by transabdominal ultrasound were examined.

The ultrasound probe was covered with sterile glove after gel application and placed on sagittal axis directly on the perineal region.

The image was frozen at rest on one side of screen with visualization of the inferior edge of symphysis pubis, bladder, urethra, urethra-vesical angle and the vagina.

Then the patient was asked to do serial coughs, Valsalva manoeuvers and the image frozen on the other side of the screen.

The following parameters were measured:

a) Bladder neck descent $(\mathrm{BN})$ in relation to the inferior-posterior margin of symphysis pubis

b) Funneling of the proximal urethra or bladder neck

c) Presence of cystocele

d) Measurement of urethral diameter in the sagittal view (inner to inner).

e) Alpha angle between the vertical axis of the proximal urethra and a line passing in the central axis of symphysis pubis

f) Beta angle or posterior urethrovesical angle (PUVA) which is the angle between the proximal urethra and the posterior vesical wall

g) Color Doppler to detect urine motion through urethra during leak

\section{Statistical analysis}

Data were statistically described in terms of mean \pm standard deviation $( \pm \mathrm{SD})$, median and range, or frequencies (number of cases) and percentages when appropriate. Comparison of numerical variables between the study groups was done using Student $t$ test for independent samples in comparing 2 groups when normally distributed and Mann Whitney $U$ test for independent samples when not normally distributed. Comparison of numerical variables between more than two groups was done using Kruskal Wallis test with Mann Whitney test as posthoc multiple 2-group comparisons. For comparing categorical data, Chi square $\left(\chi^{2}\right)$ test was performed. Exact test was 
used instead when the expected frequency is less than 5. Accuracy was represented using the terms sensitivity, specificity, +ve predictive value, -ve predictive value, overall accuracy, the likelihood ratio of a positive test and the likelihood ratio of a negative test. Receiver operator characteristic (ROC) analysis was used to determine the optimum cut off value for the studied diagnostic markers. $p$ values less than 0.05 was considered statistically significant. All statistical calculations were done using computer program SPSS (Statistical Package for the Social Science; SPSS Inc., Chicago, IL, USA) release 15 for Microsoft Windows (2006).

\section{Results}

This study was conducted on 52 women with clinical diagnosis of stress urinary incontinence confirmed by urodynamic study of all cases. The mean age of the studied group was $34.79 \pm 9.44$ (mean \pm S.D) and the mean parity was $2.46 \pm 1.36$. All cases were comparable regarding the BMI with a mean of $26.19 \pm 2.52$. Cases with mild SUI represented $69.2 \%$ of all cases (36/52); moderate SUI was $23.1 \%$ $(12 / 52)$ and severe SUI accounted only for $7.7 \%$ of cases $(4 / 52)$.

The sonographic parameters that showed a statistically significant difference between the 3 degrees of SUI (mild, moderate and severe) were the bladder neck descent, PUVA at Valsalva and the urethral diameter as shown in Table 1 (Figures 1-8).

The presence of severe SUI significantly related statistically to the presence of bladder neck descent, $\alpha$ angle difference (Valsalva minus Rest), PUVA at Valsalva and urethral diameter with p-values: 0.004, $0.037,0.027$ and 0.001 respectively.

Table I Showing the mean values of different ultrasound parameters in mild, moderate and severe SUI

\begin{tabular}{|c|c|c|c|c|c|}
\hline \multirow{2}{*}{ Ultrasound parameter } & \multicolumn{3}{|c|}{ SUI (urodynamic) } & \multirow{2}{*}{ p-value } & \multirow{2}{*}{ Significance } \\
\hline & Mild & Moderate & Severe & & \\
\hline Bladder neck descent (mm) & $14.53 \pm 2.13$ & $18.67 \pm 2.02$ & $21.50 \pm 3.51$ & $<0.05$ & S \\
\hline$\alpha$-angle at rest (degrees $\left.{ }^{\circ}\right)$ & $78.39 \pm 19.3$ & $74.92 \pm 15.38$ & $77.75 \pm 18.25$ & 0.705 & NS \\
\hline$\alpha$-angle at Valsalva $\left(\right.$ degrees $^{\circ}$ ) & $100.36 \pm 18.01$ & $108.5 \pm 12.43$ & $\mid 27.0 \pm 14.33$ & 0.171 & NS \\
\hline$\alpha$-angle difference & $31.17 \pm 7.78$ & $33.67 \pm 10.59$ & $49.25 \pm 19.48$ & 0.072 & NS \\
\hline PUVA at rest (degrees $\left.{ }^{\circ}\right)$ & $124.17 \pm 8.55$ & $130.92 \pm 12.64$ & $137.50 \pm 2.18$ & 0.065 & NS \\
\hline PUVA at Valsalva (degrees ${ }^{\circ}$ ) & $150.39 \pm 7.37$ & $165.0 \pm 10.19$ & $169.0 \pm 12.19$ & $<0.05$ & $S$ \\
\hline PUVA difference & $26.22 \pm 6.85$ & $34.08 \pm 12.78$ & $31.50 \pm 3.79$ & 0.067 & NS \\
\hline Urethral diameter $(\mathrm{cm})$ & $0.20 \pm 0.09$ & $0.33 \pm 0.14$ & $0.63 \pm 0.09$ & $<0.05$ & S \\
\hline
\end{tabular}

*Values are expressed in terms of mean $\pm S$.D; $\mathrm{p}$-values where NS stands for statistical non-significant difference, $\mathrm{S}$ stands for statistical significant difference.Pvalue $<0.05$ is significant.

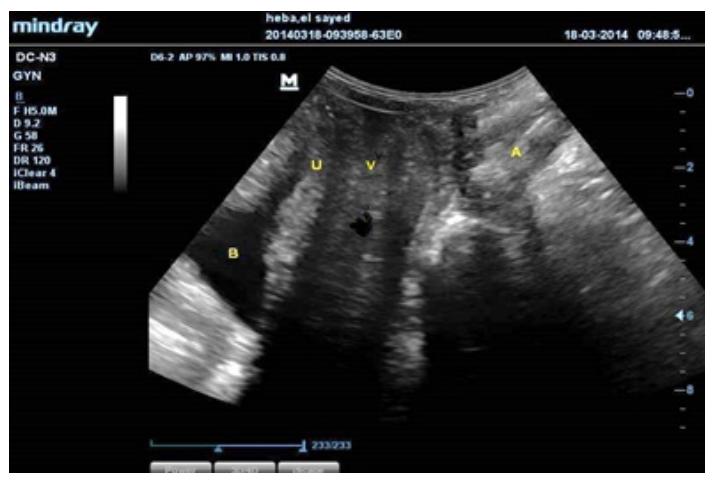

Figure I normal sagittal view (Bladder, U: urethra ,V:vagina, A:ampulla of rectum).

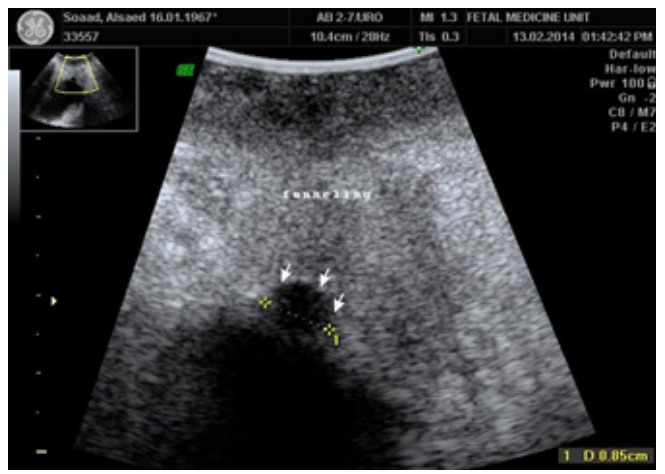

Figure 2 Funneling of proximal urethra at rest. 


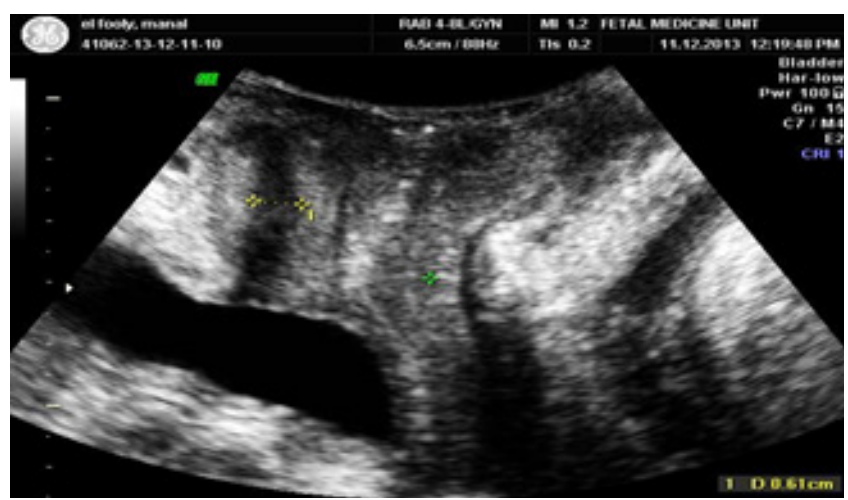

Figure 3 Urethral diameter in sagittal view suggestive of intrinsic sphincteric deficiency.
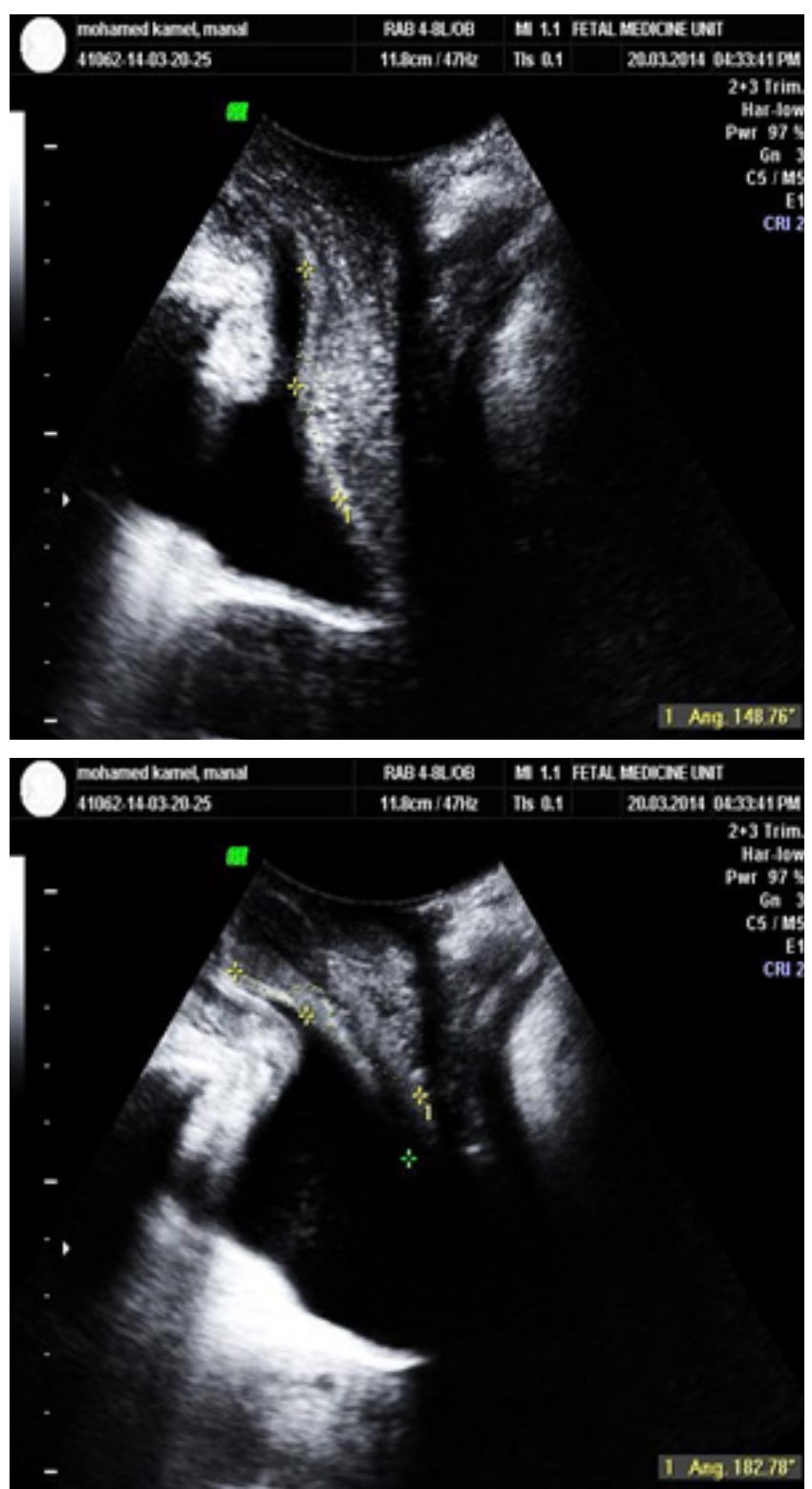

Figure 4 Beta angle at rest and with straining.
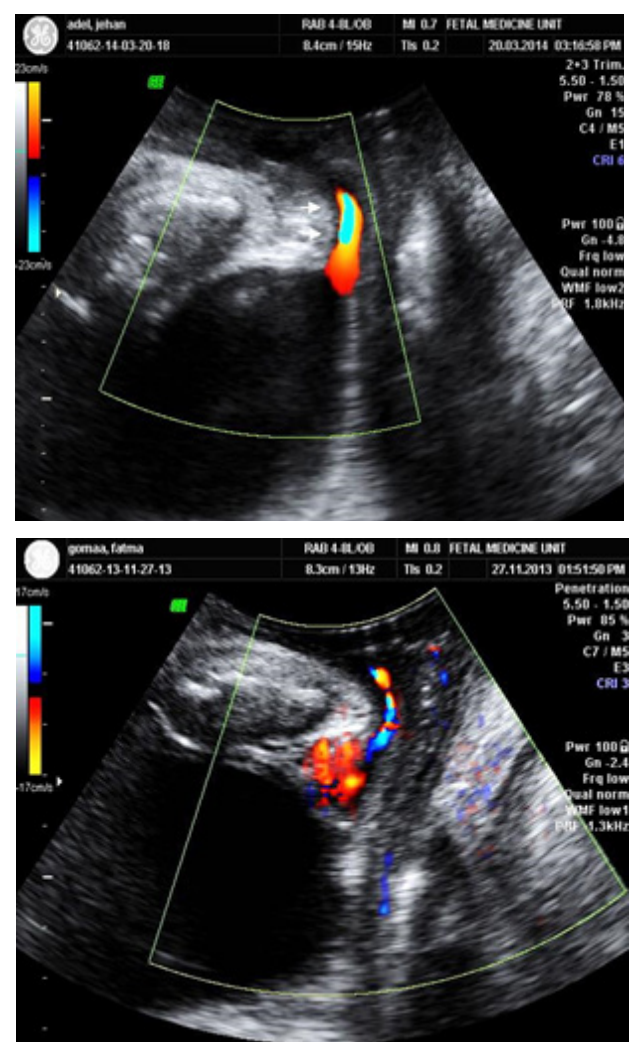

Figure 5 Escape of urine detected with color Doppler.
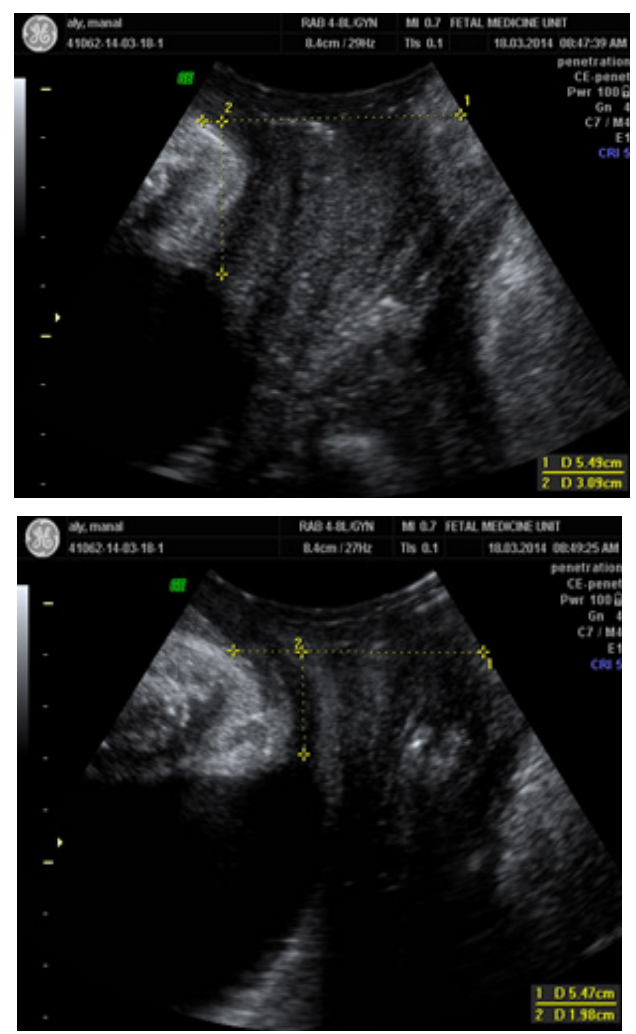

Figure 6 Bladder neck descent (displacement). 


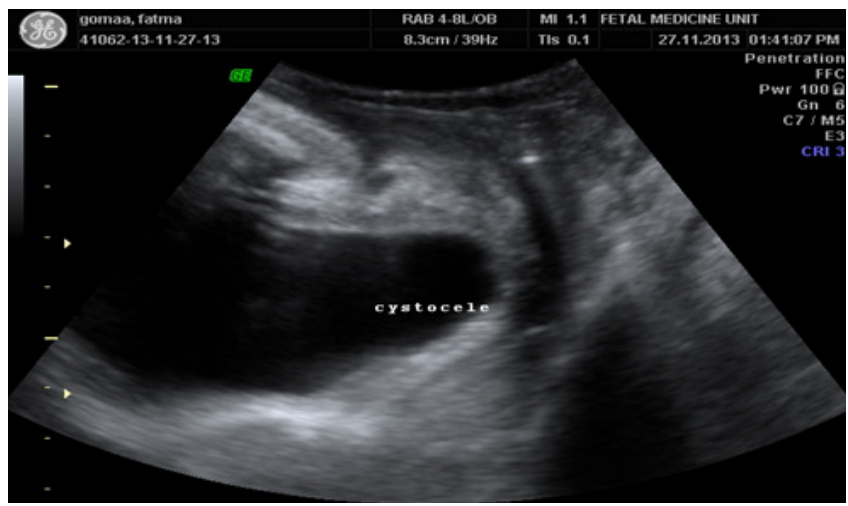

Figure 7 Cystocele.

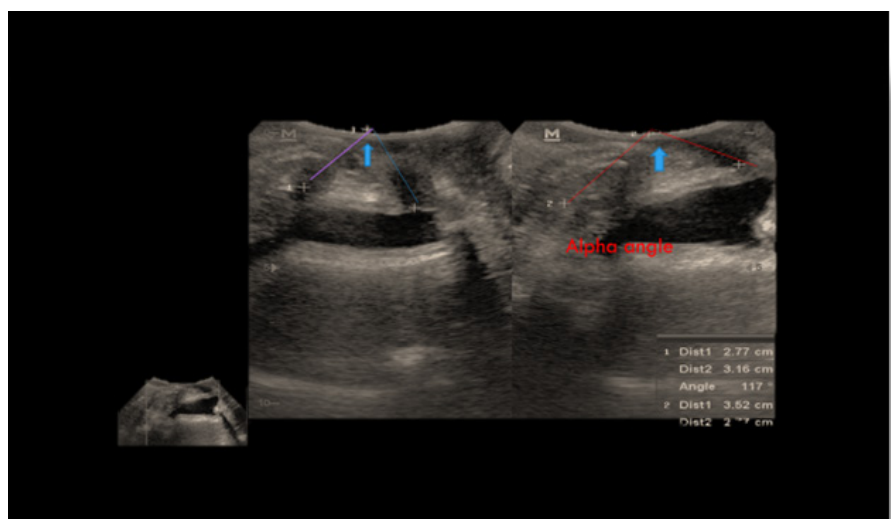

These parameters except for the $\alpha$-angle difference also showed a statistically significant difference between cases of severe SUI and other grades of SUI. $\alpha$-angle difference specifically showed a significant relation to cases of severe SUI.

\section{Statistical significant difference.P-value $<0.05$ is significant}

Bladder neck descent, PUVA at Valsalva and the urethral diameter were the sonographic parameters that showed a statistically significant difference between mild and moderate SUI with p-values; $<0.05$, $<0.05$ and 0.002 respectively as shown in Table 2 .

Bladder neck descent, $\alpha$-angle difference, PUVA at Valsalva and at rest and urethral diameter were the parameters that showed a statistically significant difference between mild and severe SUI with p-values: $0.001,0.028,0.04,0.009$ and 0.001 respectively. However, only the $\alpha$-angle at Valsalva and the urethral diameter showed a significant difference between moderate and severe cases with p-values; 0.029 and 0.007 respectively.

$28 / 52$ cases $(53.8 \%)$ of SUI didn't show clinical evidence of cystocele; 11 cases $(21.2 \%)$ showed grade 1 cystocele and 13 cases $(25 \%)$ showed grade 2 cystocele. The presence or absence of cystocele and also the grade of cystocele did not show a statistically significant relation to the degree of SUI; $\mathrm{p}=0.089$ and 0.086 respectively. Only $50 \%$ of cases with moderate SUI (6/12) and $50 \%$ of cases with severe SUI (2/4) showed grade 2 cystocele; $16.7 \%$ of moderate SUI cases and $25 \%$ of severe SUI cases showed grade 1 cystocele as shown in Table 3.

Figure 8 Alpha angle demonstration.

Table 2 Shows a comparison between the grades of SUI and various ultrasound parameters regarding their $\mathrm{p}$-values

\begin{tabular}{|c|c|c|c|c|c|c|}
\hline \multirow{2}{*}{$\begin{array}{l}\text { Ultrasound parameter } \\
\text { Bladder neck descent }(\mathrm{mm})\end{array}$} & \multicolumn{2}{|c|}{$\begin{array}{l}\text { Comparing mild and } \\
\text { moderate SUI } \\
\text { p-value }\end{array}$} & \multicolumn{2}{|c|}{$\begin{array}{l}\text { Comparing mild and } \\
\text { severe SUI } \\
\text { p-value }\end{array}$} & \multicolumn{2}{|c|}{$\begin{array}{l}\text { Comparing moderate and } \\
\text { severe SUI } \\
\text { p-value }\end{array}$} \\
\hline & $<0.05$ & $S$ & 0.001 & $\mathrm{~S}$ & 0.142 & NS \\
\hline$\alpha$-angle at rest (degrees ${ }^{\circ}$ ) & 0.405 & NS & 0.804 & NS & 0.856 & NS \\
\hline$\alpha$-angle at Valsalva (degrees ${ }^{\circ}$ ) & 0.821 & NS & 0.104 & NS & 0.029 & $S$ \\
\hline$\alpha$-angle difference & 0.328 & NS & 0.028 & $S$ & 0.145 & NS \\
\hline PUVA at rest $\left(\right.$ degrees $\left.^{\circ}\right)$ & 0.14 & NS & 0.04 & $S$ & 0.43 & NS \\
\hline PUVA at Valsalva (degrees ${ }^{\circ}$ ) & $<0.05$ & $S$ & 0.009 & $S$ & 0.429 & NS \\
\hline PUVA difference & 0.07 & NS & 0.082 & NS & 0.716 & NS \\
\hline Urethral diameter $(\mathrm{cm})$ & 0.002 & $\mathrm{~S}$ & 0.001 & $\mathrm{~S}$ & 0.007 & $S$ \\
\hline
\end{tabular}

Table 3 Showing the relation between various grades of cystocele and SUI in the studied group

\begin{tabular}{lllll}
\hline Grade & Mild SUI & Moderate SUI & Severe SUI & Total \\
& $(\mathbf{n = 3 6 )}$ & $(\mathbf{n = 1 2 )}$ & $\mathbf{( n = 4 )}$ & $(\mathbf{n}=\mathbf{5 2})$ \\
\hline Cystocele 0 (absent) & $23(63.9 \%)$ & $4(33.3 \%)$ & $\mathrm{I}(25 \%)$ & $28(53.8 \%)$ \\
I & $8(22.2 \%)$ & $2(16.7 \%)$ & $1(25 \%)$ & $\mathrm{II}(21.2 \%)$ \\
2 & $5(13.5 \%)$ & $6(50 \%)$ & $2(50 \%)$ & $13(25 \%)$ \\
\hline
\end{tabular}

*Data presented as frequency and \%. 
The majority (83.3\%) of cases with cystocele did not show funneling upon ultrasound examination. Funneling did not statistically relate to the presence or absence of cystocele, $\mathrm{p}=0.397$. However, concerning the relationship between funneling and the various degrees of SUI, it was statistically significant with $\mathrm{p}=0.011$. Most of the mild cases of SUI (97.2\%) didn't show funneling, also the greater majority of moderate $(66.7 \%)$ and severe SUI cases $(75 \%)$ showed no funneling on ultrasound as shown in Table 4 .

However, when studying funneling in cases with severe SUI in comparison to those without severe SUI, when comparing the various studied ultrasound parameters to the presence or absence of cystocele, only 2 parameters i.e. PUVA-Rest and PUVA-Valsalva showed a statistically significant difference with $p=0.047$ and 0.042 respectively. The remaining parameters were statistically non-significant.

Table 5 shows the prediction of severe SUI at different cut-offs identified by ultrasound parameters. At each cut-off, the optimal measurements of different parameters were determined using ROC curve with the highest sensitivity and specificity.

Table 4 Showing the relation between funneling (by ultrasound) and cystocele and degrees of SUI

\begin{tabular}{|c|c|c|c|c|c|c|c|}
\hline & \multicolumn{2}{|c|}{ Cystocele } & \multirow[b]{2}{*}{$p$-value } & \multicolumn{3}{|c|}{ SUI $(n=52)$} & \multirow[b]{2}{*}{ p-value } \\
\hline & $\begin{array}{l}\text { Absent } \\
(n=28)\end{array}$ & $\begin{array}{l}\text { Present } \\
(n=24)\end{array}$ & & Mild & Moderate & Severe & \\
\hline Funnelling No & $26(92.9 \%)$ & $20(83.3 \%)$ & \multirow{2}{*}{0.397} & $35(97.2 \%)$ & $8(66.7 \%)$ & $3(75 \%)$ & \multirow{2}{*}{0.011} \\
\hline Yes & $2(7.1 \%)$ & 4 (16.7\%) & & $\mathrm{I}(2.8 \%)$ & $4(33.3 \%)$ & $I(25 \%)$ & \\
\hline
\end{tabular}

Table 5 Sensitivity, specificity and AUC of significant ultrasound parameters in prediction of severe SUI

\begin{tabular}{|c|c|c|c|c|}
\hline Ultrasound parameters & Cut-off value & Sensitivity & Specificity & Area under the curve (AUC) \\
\hline Bladder neck descent(mm) & 17.5 & $100 \%$ & $78 \%$ & 0.93 \\
\hline$\alpha$-angle difference(degrees ${ }^{\circ}$ ) & $41.5^{\circ}$ & $75 \%$ & $82 \%$ & 0.815 \\
\hline PUVA at Valsalva (degrees ${ }^{\circ}$ ) & $170^{\circ}$ & $75 \%$ & $90 \%$ & 0.836 \\
\hline Urethral diameter $(\mathrm{cm})$ & 0.45 & $100 \%$ & $96 \%$ & 0.99 \\
\hline
\end{tabular}

\section{Discussion}

Urinary incontinence is one of the most embarrassing conditions in females that can make them socially shy, inactive and at some point considered a handicap if not adequately treated.

Stress urinary incontinence is a type in which urine leaks with coughing, sneezing, jumping or doing regular workout. The fact that we have a gold standard management for all cases of stress has been misleading and deceiving mostly due to failure of treatment or recurrence.

The debate existed for years and possibly yet where the compelling question was: 'Do we have to restore anatomical defect or rather the physiological dysfunction of the bladder and urethral unit?"

Observation of history along with cystourethrography, urodynamic, perineal or interoital ultrasound, MRI, gave clues that some anatomical changes in bladder neck, bladder descent, rotational angles, urethral diameter, hypermobility could help us in understanding the problem insitu, even grading the cases accordingly and choosing one or even more than one surgical procedure to effect treatment.

In the current study, we recruited 52 female cases diagnosed to have stress urinary incontinence based on history, 3- day diary, examination and confirmed by urodynamic study.

The cases were then graded into mild, moderate, severe using Valsalva leak point pressure as described previously. Transperineal ultrasound which is an easy, non invasive method of diagnosis was evaluated as a complementary tool for diagnosis and grading of cases of stress urinary incontinence.

The mean age of the studied group was $34.79 \pm 9.44($ mean \pm S.D) and the mean parity was $2.46 \pm 1.36$. All cases were comparable regarding the BMI with a mean of $26.19 \pm 2$.

The literature includes many studies conducted for evaluation of transperineal ultrasound in the assessment of bladder neck displacement, different rotational angles of the urethra, the urethral diameter and other anatomical defects.

In this current study, the aim was to investigate various ultrasound parameters and to trying to reach with a clear confidence the possible, cut off values to differentiate the grades of stress urinary incontinence using just a simple, non sophisticated ultrasound machine.

Bladder neck descent or vertical component of bladder neck mobility in the current study was significant for cases with severe SUI with cutoff value $17.5 \mathrm{~mm}$ (sensitivity $100 \%$ and specificity $78 \%$ ). There was a statistically significant difference comparing severe cases and mild cases, but no statistical significance comparing the moderate and severe cases. In a similar study, Sweed MS et al. ${ }^{8}$ found a mobility $>10 \mathrm{~mm}$ in cases with SUI while it was $3.2 \mathrm{~mm}$ in control group. Other studies like Dietz HP $^{9}$ gave a wide range of bladder neck mobility in stress incontinence cases compared to the controls but without differentiating mild from moderate and severe cases.

The $\alpha$-angle measurement in this study showed no statistical significance in severe cases of SUI both at rest and at Valsalva but the $\alpha$-angle difference was significant with cutoff value of 41.5 degree (sensitivity $75 \%$ and specificity $82 \%$ ). Comparing severe cases and mild cases there was only statistical significance in $\alpha$-angle difference but no difference at rest or valsalva. Comparison between severe cases and moderate cases of SUI there was only statistical difference in $\alpha$-angle at Valsalva but no difference at rest and in $\alpha$-angle difference. 
In a study by Wasan Ismail Al-Saadi ${ }^{10}$ comparing cases with SUI with acontrol group (without SUI) the $\alpha$-angle in SUI cases was higher at both rest and Valsalva. On the contrary, Sweed MS and Sharara $\mathrm{S}$ in similar studies found that there was no difference in $\alpha$-angle between patients with SUI and control group while it was statistically significant $(p<0.001)$ in resting and straining phases of SUI patients.

The posterior urethrovesical angle ( $\beta$ angle) assessed by transperineal ultrasound has a great value in understanding the mechanism of incontinence at the bladder neck and proximal urethra. Sendag et al. ${ }^{11}$ in their study conducted on 17 controls and 30 patients with SUI found that $\beta$ angle was significantly higher at rest and Valsalva comparing stress group and control one. They found that a $\beta$ angle $>120^{\circ}$ correlates with poor support at urethrovesical portion. Another study of Al-Saadi, the threshold value for $\beta$ angle at stress was $>141.5^{\circ}$ (sensitivity $73 \%$ and specificity $80 \%$ ).

When we tried to compare $\beta$ angle at rest between mild and moderate cases there was no statistical difference, the same was true (applied) when comparing moderate and severe cases. However, we had a statistical significance $(\mathrm{p}=0.009)$ when comparing $\beta$ angle at rest between mild and severe cases.

In the present study, only severe cases of SUI had a cutoff value of $>170^{\circ}$ for the $\beta$ angle at valsalva with sensitivity and specificity ( $75 \%$ and $90 \%$ respectively). The comparison between mild cases and moderate cases regarding $\beta$ angle at valsalva was statistically significant $(\mathrm{p}<0.05)$, and similarly when comparing both mild and severe cases $(\mathrm{p}=0.009)$. The moderate and severe groups showed no statistical significance while comparing $\beta$ angle at Valsalva.

The urethral walls coaptation and integrity gained from the smooth muscle coat, the striated muscle and the vascular spongy tissue all together are of great importance in normal passive urinary incontinence.

Thus in cases of severe SUI related to ISD (intrinsic sphincteric deficiency) the problem arises as the urethral canal is transformed into a pipe like structure with no response to stressful conditions like coughing, sneezing and it remains open with loss of shutter mechanism.

In our current study, we could demonstrate that a urethral diameter of $0.45 \mathrm{~cm}$ or greater was a predictor for severe stress incontinence with a (sensitivity $100 \%$ and specificity $96 \%$ ).

Comparing mild to moderate cases regarding urethral diameter was found to be statistically significant $(\mathrm{p}=0.002)$. The same was found when comparing mild to severe cases diameter $(\mathrm{p}=0.001)$ and severe to moderate SUI by measuring urethral diameter as single predictor of severity ( $\mathrm{p}$-values $=0.001$ and 0.007 respectively).

In a similar study, Sweed Ms et al. ${ }^{8}$ found that urethral diameter was significant comparing patients with ISD and patients with SUI without ISD $(6.64 \pm 1.23 \mathrm{~mm}$ and $4.83 \pm 1.16 \mathrm{~mm}$ respectively) $(\mathrm{p}=0.03)$. Also, Oliveira et al., ${ }^{12}$ demonstrated similar results with mean urethral diameters in cases of SUI with ISD compared to those with SUI without ISD of $6.38 \mathrm{~mm}$ and $4.91 \mathrm{~mm}$ respectively.

The presence or absence of cystocele in our studyand also the grade of cystocele did not show a statistically significant relation to the degree of SUI; $\mathrm{p}=0.089$ and 0.086 respectively.

Funnelling did not statistically relate to the presence or absence of cystocele, $p=0.397$. However, concerning the relationship between funneling and the various degrees of SUI, it was statistically significant with $\mathrm{p}=0.011 .^{13-15}$

\section{Conclusion}

This study aimed at evaluation of diagnostic accuracy of transperineal ultrasound in diagnosis of female stress urinary incontinence compared to the standard urodynamics.

Interpretation of the results requested very careful and critical analysis as we tried to investigate numerous ultrasound parameters which has not been done to the best of our knowledge in a previous research.

Many reviews of literature described how to measure those parameters such as the work of Hanz Peter Dietz ${ }^{9}$ in describing the ultrasound imaging of the pelvic floor without assessing their utility in diagnosis of SUI.

After a great effort in observing and analyzing data, we came to conclusion that trans perineal ultrasound is comparable to standard urodynamic in diagnosing and classifying the degree of stress urinary incontinence in females and superior in visualization of the possible anatomical cause.

Transperineal ultrasound can be used in accurate diagnosis and grading of female urinary stress incontinence with our given cutoff values for bladder displacement, $\alpha$ angle, $\beta$ angle and urethral diameters and from this trading by transperineal ultrasound comes the novelity of our research. However, we recommend further larger-scale studies using the given cut-offs to further evaluate their usefulness and to implement the use of transperineal ultrasound as part of the routine work-up in cases of SUI as a complementary diagnostic tool to the gold standard urodynamics. Thus enabling us to plan and choose the appropriate corrective surgical procedure for SUI. Possible pre and postoperative transperineal ultrasound evaluation of SUI cases could be scope for future studies.

\section{Acknowledgments}

We would like to thank the staff members who helped us in this study in kasralainy hospital.

\section{Funding}

None.

\section{Informed consent}

Informed consent was obtained from all the individual participants included in the study.

\section{Conflicts of interest}

No potential conflict of interest was reported by the authors.

\section{References}

1. Abrams P, Cardozo L, Fall M, et al. The standardisation of terminology of lower urinary tract function: report from the Standardisation Subcommittee of the International Continence Society. Am J Obstet Gynecol. 2002;187(1):116-126.

2. Luber KM. The Definition, Prevalence, and Risk Factors for Stress Urinary Incontinence. Rev Urol. 2004;6(Suppl 3):S3-S9.

3. Rortveit G, Daltveit AK, Hannestad YS, et al. Urinary incontinence after vaginal delivery or cesarean section. $N$ Engl J Med. 2003;348:900-907. 
4. Alper T, Cetinkaya M, Okutgen S, et al. Evaluation of urethrovesical angle by ultrasound in women with and without urinary stress incontinence. Int Urogynecol J Pelvic Floor Dysfunct. 2001;12:308-311.

5. Minardi D, Piloni V, Amadi A, et al. Correlation between urodynamics and perineal ultrasound in female patients with urinary incontinence. Neurourol Urodyn. 2007;26(2):176-182.

6. Hu Y, Lou Y, Liao L, et al. Comparison of Urodynamics and Perineal Ultrasonography for the Diagnosis of Mixed Urinary Incontinence in Women. J Ultrasound Med. 2018;37(11):2647-2656.

7. George D Webster, Michael L Guralnick. Theneurourologic evaluation In: Walsh PC, Petik AB, Vaughan ED, editors. 8th ed. Philadelphia: Campell's Urology; 2002:900-930.

8. Sweed MS, Sharara S. Transperineal ultrasound evaluation of female with stress urinary incontinence. Int J Reprod Contracept Obstet Gynecol. 2016;5(3):637-641.

9. Dietz HP. Ultrasound imaging of the pelvic floor. Ultrasound J Obstet Gynecol. 2004;23:80-92.
10. Wasan Ismail Al-Saadi. Transperineal ultrasonography in stress urinary incontinence: the significance of urethral rotation angles. Arab Journal of Urology. 2016;14:66-71.

11. Sendag F, Vidinli H, Kazandi M, et al. Role of perineal sonography in the evaluation of patients with stress urinary incontinence. Aust N ZJ Obstet Gynaecol. 2003;43:54-57.

12. Oliveira FR, Ramos JG, Martins-Costa S. Translabial ultrasonography in the assessment of urethral diameter and intrinsic urethral sphinctericdeficiency. J Ultrasound Med. 2006;25(9):1153-1158.

13. Yang JM, Huang WC. Discrimination of bladder disorders in female lower urinary tract symptoms on ultrasound cystourethrography. J Ultrasound Med. 2002;21:1249-1255.

14. Akram W. Correlation between genuine stress incontinence in women and bladder neck mobility as assessed by inter labial ultrasound scan. Iraqi $J$ Comm Med. 2010;3:169-172.

15. Urinary incontinence in women: management Clinical guideline [CG171]. National Institute for Health and Care Excellence; 2013. 